\title{
REFLECTIVE PAPER
}

The framework of a generic DProf programme - a reflection on its design, the relational dimension for candidates and advisors and the potential for knowledge co-creation

\author{
${ }^{1}$ A.J. Fillery-Travis, \\ Institute of Work Based Learning, \\ Middlesex University, \\ London
}

Keywords: Professional Doctorate, Knowledge Co-creation, Practitioner Research, relational dimension

${ }^{1}$ Dr Annette Fillery-Travis, Director of Programmes (DProf), Institute for Work Based Learning, Middlesex University, London NW4 4BT, t: 02084115689, e: a.fillerytravis@mdx.ac.uk 


\section{Abstract}

This paper critically engages with the pedagogical design of a generic Professional Doctorate Programme as a framework for creation of actionable knowledge within the practice of both advisor and candidate. Within this exploration the relational dimensions of the advisorcandidate interaction are identified and their potential impact partially explored.

The Professional Doctorate at Middlesex University has developed over the last fifteen year with over 180 candidates either graduated or currently studying. It is an individually negotiated programme where the primary resource for the candidate is the one to one support of the academic advisor and the consultant. Within this paper the essential features of the workbased learning programme are described. These are designed to enable individual change and to provide high level professional development for advanced practitioners. The passionate and creative stance of the advanced practitioners that engage with the programme is then considered and how their practice is knowledge producing and validating in its own right enabling it to be described as epistemic. The engagement of these practitioners with research and enquiry is considered and specifically the relational aspects of both the focus of the research and the interaction with the supervisory team.

Finally the Professional Doctorate is considered in light of whether it is a vehicle for cocreation of actionable knowledge as defined by . The result is not straightforward and requires a consideration of both the power distribution within, and leadership of, the research activity. Specifically the challenges that the advisory team are confronted with identifies that is it as much a process of individual change for them as for their candidates. 


\section{Introduction}

The Professional Doctorate has been part of the doctoral landscape for the last two decades and it is only now that debates as to its 'newness' in terms of rigor and validity are subsiding to be replaced with the more mature debate as to the variations in design, their impact and their role as advanced professional development for senior practitioners.

As identified by Maxwell et al (and further explored in the introduction to the Middlesex University DProf by Lester ) doctorates for practitioners grew from two distinct perspectives on knowledge production. The first generation professional doctorates developed from the 'academic' perspective of Mode 1 knowledge production. They take practice as a focus for research with the researcher investigating a particular aspect of the activity. The researcher is in essence separate and remote from the practice and an observer of it with the locus of enquiry being within the University.

The second generation professional doctorates are more aligned to Mode 2 where the production of knowledge is considered within its context and with the full engagement of the end-user of that knowledge. The researcher in this case is a scholar-practitioner embedded within their practice and their research. This is highly sympathetic to Schon's view of the interdependence of knowledge and practice with each developing the other. In each case the disciplinary focus of the doctorate is maintained through the professional identity of the practitioner. This evolution of structure has contributed to the growth of the number of programmes offered; by 2009 the number of professional doctorates in the UK was 308 with the largest number offered in the subject areas of Education, Business and Engineering providing a total of over 3600 students . 
A third type of Professional Doctorate has emerged in the UK and Australia which is not discipline or profession specific and has been identified as a generic DProf (Doctorate of Professional Studies or Professional Practice) . Originally developed within Middlesex University in 1998 it is based upon the concept of knowledge generation within practice in which the overarching discipline provides a framing of the work but the content is the knowledge-in-use;

'Its focus is on generating practical action which also represents high-level professional scholarship....addressing complex professional, organisational and social issues.' Lester 2004 p758

Research for this doctorate is again situated within the workplace and practitioner research is at the core of its vision, enabling advanced practitioners to undertake a doctoral programme where the focus of their research is their area of practice and work. The individuals who undertake this programme are senior in their field; engaged in high level non-routine tasks, often trans-disciplinary in nature and operating in environments that are highly ambiguous.

\section{The Programme Design}

Work Based Learning (WBL) has been a pedagogic framework for the development of senior practitioners through professional Master and Doctorate programmes for over three decades. These degrees are now well established in the UK with a broad range of HEI's providing professional doctorates in a number of professional areas. These professionspecific doctorates often contain specific taught modules taken prior to the completion of a final research project . The professional doctorate at Middlesex University is, in contrast, a generic doctorate where students (identified as candidates) undertake a project that is built around their specific work/practice activities . As identified previously these activities are not 
restricted to recognised professional practices nor indeed paid work but can embrace voluntary and unpaid activities. The programme specifically seeks to make a contribution to practice through impact at the organisational or community level.

At its most fundamental the DProf programme design is based around the generic elements of an individual change process . This process starts with a review of the learning that has brought the individual to the current point in their professional development, the goal of the change initiative is then identified and a detailed plan constructed of how that goal will be achieved. This plan is then implemented with an appropriate monitoring of progress against that goal.

In the generic DProf programme the process also starts with the candidates undertaking a review their own learning to date. This requires a critical reflection upon both their professional development and practice to date. Candidates can at this point also make a claim for the recognition and accreditation of their prior learning (APEL) from relevant certificated programmes and/or experiential learning. Specifically a claim for advanced professional learning can be made which allows the exploration of the non-routine elements of the candidate's practice and how they have developed specific and high level expertise or mastery of a professional area. This consideration of learning and the required self assessment at both Master and Doctorate levels leads to the development of sophisticated analysis skills which the candidate then draws upon throughout the reminder of their programme. The candidate is supported in this work by resource handbooks, a virtual learning environment and through tutorials and feedback from a dedicated adviser. The advisor is not a conventional PhD Supervisor (hence the term adviser). They are not subject experts but use a coaching mode of interaction with the candidate to provide support for reflection thereby enabling connections to be made between past, current and future learning . 
This enrichment of the candidate's self awareness becomes the corner stone of further professional development and drives the formulation of the programme plan itself - the next submission in the programme. Within this document the candidate identifies the learning sought from the programme and the research/project work to be undertaken to achieve this learning. At its core is a three way agreement between the candidate, the University (identifying the proposed work is suitable for doctoral level work) and their community of practice, workplace or profession (identifying the value to practice of the proposed work). The successful completion of this plan relies not only on reflection upon practice but also on an analysis of requirements for further learning thus embodying the concept of reflexivity in the application of the subsequent learning to their work.

The advisers support candidates through this process by assisting them to develop a clear vision of their future and the means through project work by which they can achieve their goals. Throughout this process the advisor is not an expert in the organisational context or in the multi-disciplinary focus of the candidate's work. The advisor is required to sit with a relatively high degree of ambiguity and uncertainty as they cannot control or dictate the learning sought or achieved by the candidate. The candidate is also experiencing appropriate uncertainty in relation to the development and progress of their programme. The uncertainty of the candidate and the advisor is shared, albeit from different perspectives. This shared exploration of uncertainty is at the heart of the critical reflective dialogue in which they engage. At this point a subject specialist will also join the advisor to complete the supervisory panel. The consultant's role is one closest to a conventional PhD Supervisor and ensures the currency of scholarship and innovation.

The proposed project work is the vehicle by which the candidate generates new knowledge using appropriate practitioner researcher and work based learning approaches. During the project the adviser maintains a relationship with their candidate over what can be 
several years. A genuine, authentic relationship and approachable style of advising/supervising are critical to manage the inevitable changes and challenges that will occur during this period

The DProf is a complex programme requiring significant self direction on the part of the candidate and advanced facilitation/coaching skills from the advisor. Clearly this complexity raises a number of questions about how the candidate engages with doctorate level learning both within their own practice/work activities and through researching practice itself. In the rest of this paper I will reflect upon some of these issues by considering what we mean by practice for our candidates, how their practice can be seen to generate research and finally how the relational aspects of both their practice and research provide challenges for the advisory team and whether the overall process can be identified as co-creation.

\section{Our candidates, their practice and their knowledge}

What do we define as practice within this context? Historically practice has been the province of the professions and the 'professional' is considered as an identity based on the rational, scientific and impartial use of knowledge . As Gherardi identifies there is a great difficulty in defining practice 'due to the various epistemic positioning of different researchers'. We cannot explore this in detail here so we define practice more generally as human activities 'centrally organised... around shared practical understanding' . Practice in either definition provides for the identity and work of the practitioner to be socially embedded and this has a number of major implications for us when we are considering the professional development of those advanced in their field of work. For example; priority is given to certain forms of knowledge within a field of practice and this in turn is shaped by both context and environment. As identified within Lane and Corrie (2006) 'we work, think and act within the targets set by others' as we have internalised the regimes of truth that are 
specifically operating. This has led in the past to the perception of practice as regular and routine responses to concrete experiences within constrained environments.

A moment's reflection is all that is required for us to identify that instrumental problem solving or rule-following is not the whole story of practice. As Schon (1987) identifies mastery is concerned with 'the action in the field' not the taught operational procedure. The art of practice is learned through experience and the 'knowing how' as opposed to the 'knowing about'. The complexity this provides is thrown into sharp relief when the current social transitions are also considered and the shift from industrialisation to the knowledge society. We can identify that as individuals we are

'confronted with knowledge based and knowledge centred activities in many areas of social life' Schatzki et al, 2001 p176

Practitioners are required to categorise, analyse and critical engage with knowledge from a variety of settings before applying and testing within their own practice. This knowledge -creating and - validating defines epistemic practice. Originally constrained within the scientific professions the nature of work within knowledge societies requires the recognition of epistemic practice within the work activities of many advanced practitioners in a variety of contexts.

\section{Creativity and desire}

How does this form of practice impact upon the professional development of such individuals? The first element which comes to mind is the highly tacit nature of the knowledge which underpins individual practice. Indeed there is an interesting definition of expertise as 'the ability to function fluently and flexibly in complex domains without being able to describe or theorise one's expertise' . The expert musician can fluff their performance 
as soon as they become conscious of the process of producing it - their practice. That being said a deconstruction of practice to illuminate and provide the bedrock for further development is an essential element of the meta-model approach to development where the component or contributing elements of a model of theory or practice are made explicit and critically engaged with in terms of congruency and efficacy. The use of the review of learning at the start of the DProf programme is one vehicle for such an approach.

No doubt routine activity, and the knowledge that underpins it, is a significant part of practice but it is not the epistemic practice of knowledge generation and validation. As we explore epistemic practice we are concerned with the issues that arise when the practitioner is acting out of their routine as they are confronted by the non predictable and the ambiguous. Here the individual 'steps back' or becomes dissociated from the object of their practice (process, activity etc) which is problematic or 'incomplete' i.e. it has unknowns which are complex and liable to 'unfold' into further uncertainties. This dissociation allows for the investigation and examination of the object as the practitioner seeks to know it. This desire or wanting provides for real pleasure and engagement in the exploration. has written on the relational aspects of expertise and the 'chain of wanting' which can form a basis for knowledge activities and provides for the satisfaction experienced by experts within their practice. Her definition of experience is 'an arousal of the processing capabilities and sensitivities of the person'.

Our experience of the candidates who want to engage with a professional doctorate is of the practitioner engaged in what Knorr-Cetina (1999) identifies as epistemic practice: passionate and creative individuals engaged in non-routine tasks operating in environments which are highly ambiguous. As they explore their professional learning to date and prepare their APEL claims (which can be made at Master and Doctorate level) the highly creative and generative nature of the work they have undertaken in their practice is revealed. 
Clearly the nature of practice and the objects we are considering in this paper mean that there is never a time when the process of knowing and the 'chain of wanting' comes to an end. Therefore the advanced practitioner enters into a process of continual exploration or research into knowledge objects within practice.

\section{Practice and research}

This raises a series of questions about how practice can be described as engaging with research, incorporating change and participating in the 'engrossment and excitement of research work' (Knorr-Carin, 1999). The theory/practice divide has been explored extensively within a range of literatures from nursing to marketing. Traditionally universities were considered as the primary creators and custodians of knowledge; able to judge its credibility and robustness. Within the professions there was a nod towards practitioner research through the practice literature e.g. medical case studies, but these were in general of secondary importance to the development of an academic body of knowledge.

Within the developing knowledge economy Gibbons et al, has postulated that the mode of knowledge production has moved away from Mode 1 back to Mode 2 identified by transdisciplinary working aimed at specific applications through the collaborative engagement of networks of investigators. Such a research production mode uses fluid networks of workers contributing to the 'solution' of a single issue of social and political import. These networks engage not only the scientific elite but also other 'actors' such as practitioners and policy makers. Carvalho de Mello and Etzkowitz's ) triple helix model describes the resulting dynamic and fluctuating interplay between university-industrygovernment.

Thus the conventional linear model of innovation where research is seen as the creative first stage in a process, leading from research through to the creation of technique/product 
ending in application within a practice setting, is no longer seen to apply. As Salter et al so eloquently state 'such a model is dead.' Kealey argues that there is a far more complex interaction between innovation and application. Knowledge transfer can no longer simply encompass the one-way flow from university to practitioner - it must be two way! Easy enough to write but the 145 million hits on Google returned for the search term 'academic practitioner divide' is perhaps a measure of the persistence of this divide. At the heart of the issue are the differences in the values and ideologies of the very separate communities of researchers and practitioners which get in the way of communication and exploitation. Not only are there issues of focus, mode of enquiry or timescale and resources there is also a distinct difference between the questions academics ask and the problems and questions that practitioners face

There are, of course, voices from both sides of the divide that see the inclusion of practitioner perspectives as detrimental to the robustness of the research; specifically through the use of practitioner research approaches. But practitioners do not always see rigorous methodologies as relevant or helpful to them . This rigor- relevance dilemma is at the heart of work based learning approaches to enquiry and has been part of the ongoing exploration of practitioner methodologies.

We have already identified the emotional investment in epistemic practice and Bartunek identifies an interesting, relational perspective on the issues of communication between the two communities. Using the categorisation of rhetoric derived by Aristotle she identifies academic writing as operating in the arena of logos which emphasis' logic and clarity of argument. Pathos is generally associated with emotional appeal to values, beliefs and affect in an imaginative way which moves the reader to action. Ethos refers to credibility and trustworthiness. Aristotle argued that all three were required within a text however different dissemination routes may favour one element over the other. Bartunek contributes 
her own experience on this point and identifies the need for pathos to appeal to a practitioner audience and my own experience would confirm such a view. Practitioners value 'resonance' with their own practice and that will include their emotional involvement with that practice. This is reinforced by several studies which have identified that individuals seek and interpret information in ways which preserve their self image. Clearly this will influence how research is received within the practitioner community.

The development of practice ahead of research evidence has also thrown many practitioners into the role of knowledge producers or researchers as they develop their own reflective practice. The scholar practitioner, scientist practitioner and practitioner researcher are all varying descriptions of the practitioner who operates at the interface of practice and research .

'We suspected that the scholar-practitioner could best be understood as a continuum of roles, rather than just one identity where pure scholar and pure practitioner anchor each end of the continuum. Individuals may place themselves at different points on the continuum as the emphasis in their work shifts, their careers unfold, and they form different partnerships and collaborations' Wasserman \& Kram (2009) p15

But the context of the theory/practice divide has changed and with it the drivers for communication. There is also a commercial imperative operating as practitioners are presented with intensified competition for their services and are receptive to what can give them an advantage in the market. They have also not ignored the usefulness of research tools within their own practice. Action Research and Appreciative Inquiry methods are now common within organisational development providing practitioners with an increased familiarity with research. For academics, the call is urgent to develop employer engagement with higher education institutions and secure research funding from the private sector . 
It is such considerations that have led to the call for a relational scholarship of integration (Boyer, Bartunek,) . Within such a scholarship the complimentarily of the knowledge base of both communities can be explored by fostering positive mutual relationships .

'Academics need to enter into and understand practitioners' worlds and modes of knowing as well as appreciating the complexities of practitioners experience and knowledge'

Such relationships are not easily won and it is commonly acknowledged that it takes considerable relational skill to communicate across the boundaries and negotiate the issues of rigor and relevance. The DProf Advisor role sits at this interface and must maintain respect for the expertise of the candidate specifically in the multidisciplinary context of their practice and research. As part of their programme plan the candidate is also engaged in negotiating their role, as scholar-practitioner, at this boundary with the academic community and with their professional community.

\section{The relational dimension}

I have identified within this paper two specific relational aspects to the practice of advanced professionals on this type of programme.

- The relational engagement of the candidate with the 'chain of wanting'; the search for knowing within practice. This is epitomised by the real passion I have experienced from candidates about their focus of enquiry and which sustains them through the enquiry process.

- The relational requirements of the co-producing learning partnership itself for both the advisor and candidate as they negotiate their positions at the interface of theory and practice. 
So how are these issues acknowledged and addressed within the DProf programme design and the advisory relationship? Conventional supervisory roles for higher degrees concentrate upon the generation of research training and research outcomes. They provide students with the opportunity to achieve their professional or academic goal and to learn about research within an academic community operating on pre- defined standards. In return for their contribution to this learning the supervisor has a willing worker on a research project within her/his area of expertise and own research focus.

As identified by Lee in the supervision of $\mathrm{PhDs}$ (and we would suggest Doctorates in general) the relationship is

'more private than any other scene of teaching and learning' p 136

The purpose of conventional $\mathrm{PhD}$ supervision is considered as providing for the socialisation into the demands and rigors of an academic scholarly and research culture' and the production of an 'autonomous independent scholar who is, in effect, independent of their context and free from the outside world'. The paradox this provides for, in terms of supervision which itself implies distinct dependency, is discussed in detail within the paper but throughout the work the concept of 'mastery' is identified with the Supervisor as a credentialed seasoned researcher. Within the DProf the idea of autonomous scholar is replaced to some extent by the concept of an advanced practitioner who has mastered the 'practices of self'- self appraisal/reflection on practice, self regulation and self examination .

Project work within higher WBL degrees, offers a radical alternative to this convention as explored by Boud and Costley. Within this research they identify and expand upon the move 'to focus learning in the 'real-world' projects of individuals and groups doing 'realtime' work, paid or unpaid'. 
As identified above the projects are the subject of programme plans explicitly drawn up between the candidate, their organisation and the university. This removes the project from both the location of the university and from the expertise or discipline base of the research supervisor. The knowledge is transdisciplinary and practice-based so the student becomes the 'expert' in terms of the existing context and knowledge boundaries. As a scholarpractitioner the candidate will be drawing upon a range of resources from themselves, within the work context and the university. They will be designing the project outcomes for impact within the work context as well as achieving academic standards. The result is a shift in power and judgement from the supervisor towards the student. The resulting collaborative engagement between supervisor and student is acknowledged within WBL programmes by the change in name from supervisor to advisor and student to candidate.

Clearly the role of advisor is profoundly different from conventional research supervisor and requires a range of specific competencies over and above that of conventional research expertise. Boud and Costley found five clusters of competencies:

- Knowledge of work and its context - working cultures; their restriction and opportunities

- Learning consultancy skills - acknowledging candidates knowledge base, identification of learning opportunities, construction of project within the work context

- Transdisciplinary awareness -ability to identity and communicate knowledge which embraces a range of disciplines

- Enquiry approaches - knowledge of flexible and collaborative methods of enquiry leading to research and development opportunities 
- Reflexivity and reviewing skills -a reflective and evaluative approach which incorporates both self awareness and management with formalised assessment protocols and procedures.

It is in the consideration of these competencies that a description of project advisor as advisor-as-coach becomes apparent. Specifically the aim of advising has shifted from achievement of technical outputs to development of the learning of the candidate. The projects are learner managed with a negotiated contract identifying fully the expectations of learner, organisation and advisor (through the university).

As identified by Boud and Costley

'To support project work now is to find ways of assisting students to develop the expertise needed in any given situation... There is little appropriate didactic role in transmitting knowledge.'

It is perhaps now clear why we would suggest that an advisor-as-coach construct is a more unified description of the advisory role to advanced practitioners on a DProf programme. The coaching style of the advisor will respond to the ability of the candidate to engage in higher level analysis and reflection and we would expect a fluid movement between the assessor and tutor styles in response to issues such as meeting academic standards and advising on research approaches. The question for the advisor becomes not how much do you know but rather how effectively you can help others to learn .

The collaborative engagement of advisor and candidate is not without dilemmas however. Lee has identified two impacts upon supervisor style; the supervisor's concept of 
research supervision and their own experience as a doctoral student. As Lee points out there is a rich tradition of mentoring within $\mathrm{PhD}$ supervisory practice drawing upon the apprenticeship model of $\mathrm{PhD}$ supervision with the aim of the development of an autonomous scholar. However, as she identifies, there are distinct power relationships which mean that friendships are problematic until after graduation. The challenges for advisors/supervisors created by the pedagogical shift from mentor to coach have not been investigated to the full and will be part of our continuing enquiry. Suffice to acknowledge here that the development of advisory practice is still in its infancy.

The collaborative engagement sought by advisors is also aspired to by $\mathrm{PhD}$ supervisors. This is described beautifully within the concept of 'improvising together' developed by Barbara Grant where she draws upon Paul Kameen's 'communal activity of coming to know' . Within this activity supervision has a rational effect on the advisor as:

'we relish the intellectual excitement promised...we cherish opportunities to be intimately involved in the formation of new, sometimes brilliant, scholars' Grant p 272

But she also argues that the necessary counterpoint to this delight is the darker shadow of aspects of Master/slave as developed by Hegel . Difficult but 'yet often pleasurable, power relations' are part of the supervisory relationship even within the vision of supervision as mutually respectful. The collaborative engagement of the DProf dyadic of advisorcandidate may serve to reduce the contribution of Master/slave archetype to the relationship but the potential for it to arise cannot be entirely eliminated.

\section{Is this co-creation?}

In striving for collaboration are we closer to the co-creation of knowledge as developed by Antonacopoulou? She conceptualises research in practice by considering its co-creation to 
produce actionable knowledge i.e. knowledge which will have impact upon practice. She identifies the critical role of phronesis - 'the practical judgements that inform the choices made in the ways which research practice is performed'- and that research is a practice in its own right and hence it has an individual nature for each practitioner. There are multiple performances of the practice by different practitioners with their own individual purpose.

I do not agree with her separation of purpose along community lines, i.e. academics being involved in knowledge generation whereas practitioners are concerned with problem solving in the short term. This opinion derives from the argument already discussed. In my experience of practitioners involved in doctorate level work the depth and scope of the work is comparable with that of academic researchers. The scope and depth of the studies undertaken within practice in general may be more a product of the work context and the resource allocation than researcher identity. The argument concerning impact however is well made:

'Impactful research practice emerge as co-created experiences where the coresearchers have the potential to engage in a learning partnership committed to support the development of each other's agenda'

This is a point of reflection we have already discussed in relation to the triple helix model when we identified that the linear cascade of theory through to practice is not in general realised in practice. The interaction is more complex and relies on connections between all the 'actors' in the field. Co-creation is identified as a shared interest and expertise in the way practice forms, advances and establishes knowledge.

Are we, as advisors and consultants, engaged in co-creation with our candidates in the DProf? The consideration of co-creation within the DProf is not trivial. As it is defined by Antonacopoulou there is an emphasis on moving away from considering co-creation as 
purely the use of specific collaborative research methods and relationship building. It deals more specifically with a critique of the research practice itself. Central to this is the ability to ask the right questions - those which are appropriate for scholarship and for practice producing impact through knowledge which is actionable .

\section{Within the DProf:}

The research question is determined by the candidate themselves, influenced by their experience of practice and the prevailing environment. The subject specialist is there as consultant only; facilitating the rigor of the research undertaken. The choice of mode of enquiry is also candidate driven, influenced by the regimes of truth which operate within their context and their own phronesis.

The consultant and advisor generally make no contribution to the research activity itself, rarely visiting the site of the enquiry or reviewing primary data and relying on reports of the work from the candidate themselves.

This may at first glance negate the concept of co-creation but that assumes a requirement for a shared research agenda and I would suggest that this is not necessary. The candidate- consultant nexus may share similar interests but generally not the same passion for the research focus. The same can be said of the candidate-advisor nexus and given the requirement for self direction by the candidate there is an argument that this is highly appropriate. The research interests of the advisor should not overshadow or unduly influence the candidate's focus so that the research can remain firmly based in practice and work.

I would suggest that co-creation can be seen to be present if the contribution of the advisor is considered as being a facilitator of the research. In moving the leadership of the research from the professional researchers and scholars to the practitioner there is a shift in 
power which is highly significant as it places the research professionals and scholars at the service of the practitioner's research agenda. The practitioner approaches the research activity as the expert in the context and goal of the research - the work environment and the requirements of the actionable knowledge- and the advisor and consultant approach as experts in the process of research and inquiry.

Clearly the power balance between advisor and candidate is a delicate balance of allowing the expertise of the practitioner not to be overshadowed by the professional researchers. The candidate through the development of their research question seeks to produce actionable knowledge and the advisor through their holding of a learning framework and relational interaction enables that creation. This places significant emphasis on the mode of interaction between advisor and candidate and preferences a coaching engagement as we have described.

\section{Summary}

Clearly it has not been possible to consider in one paper all the questions which arise when eflecting upon the professional development of high level practitioners. Within this work I have sought to introduce some reflections upon:

- the Professional Doctorate in light of the changing description/expectation of practice and

- the relational elements which must be taken into account for candidates and advisors when considering the focus of the enquiries undertaken by practitioners and how they can be advised/supported within the research process itself and

- whether the creation of new knowledge within the doctorate can be described as co-created between the academic and practitioner. 
Studies in Higher Education

Page 


\section{References}

Adkins, B. (2009) Phd pedagogy and the changing knowledge landscapes of universities. Higher Education Research and Development Journal, 28(2), 165-177.

Antonacopoulou, E. P. (2009) Impact and scholarship: Unlearning and practising to co-create actionable knowledge. Manage. Learn. Management Learning, 40(4), 421-430.

Antonacopoulou, E. P. (2010) Beyond co-production: Practice-relevant scholarship as a foundation for delivering impact through powerful ideas. Pub. Money Manage. Public Money and Management, 30(4), 219-226.

Atkinson, T. \& Claxton, G. (2000) The intuitive practitioner : On the value of not always knowing what one is doing, (Buckingham [England]; Philadelphia, Open University Press).

Bartunek, J. M. (2007) Academic-practitioner collaboration need not require joint or relevant research: Toward a relational scholarship of integration. The Academy of Management Journal, 50(6), 1223-1333.

Berger, P. L., Berger, B. \& Kellner, H. (1974) The homeless mind : Modernization and consciousness, (New York, Vintage Books).

Boud, D. \& Costley, C. (2007) From project supervision to advising: New conceptions of the practice. Innovations in Education and Teaching International, 44(2), 119 - 130.

Boyer, E. L. (1990) Scholarship reconsidered - priorities of the professoriate, (The Carnegie Foundation for the Advancement of Teaching).

Brockbank, A. \& Mcgill, I. (2006) Facilitating reflective learning through mentoring and coaching, (London, Kogan Page).

Brown, K. \& Cooke, C. (2010) Professional doctorate awards in the uk. Report for UK Council for Graduate Education (Lichfield, Staffordshire).

Carvalho De Mello, J. M. \& Etzkowitz, H. (2000) The endless transition : Relations among social, economic and scientific development in a triple helix of university-industrygovernment relations : Third triple helix international conference, rio de janeiro, 2000, (Rio de Janeiro).

Cipd (2008) Learning and development. Report for CIPD (London).

Costley, C. \& Armsby, P. (2006) Work-based learning assessed as a field or a mode of study. Assessment \& Evaluation in Higher Education, 32(1), 21-33.

Dingman, M. E. (2004) The effects of executive coaching on job-related attitudes. Regent University.

Doncaster, K. \& Lester, S. (2002) Capability and its development: Experiences from a workbased doctorate. Studies in Higher Education, 27(1), 91-101.

Dreyfus, H. L., Rabinow, P. \& Foucault, M. (1983) Michel foucault, beyond structuralism and hermeneutics, (Chicago, University of Chicago Press).

Dunning, D., Perie, M. \& Story, A. L. (1991) Self-serving prototypes of social categories. Journal of personality and social psychology, 61(6), 957-68.

Dutton, J. E. \& Dukerich, J. M. (2006) Editors' forum: What makes research interesting? The relational foundation of research: An underappreciated dimension of interesting research. Academy of Management journal., 49(1), 21.

Evans, T. (1997) Flexible doctoral research: Emerging issues in professional doctorate programs. Studies in Continuing Education, 19(2), 174. 
Gherardi, S. (2009) Knowing and learning in practice-based studies. Available online at: http://public.eblib.com/EBLPublic/PublicView.do?ptilD=474409).

Gibbons, M. (1994) The new production of knowledge: The dynamics of science and research in contemporary societies, (London; Thousand Oaks, Calif., SAGE Publications).

Gibbons, M. (2000) Mode 2 society and the emergence of context-sensitive science. Science and Public Policy, 27(159-163.

Grant, B. (2008) Agonistic struggle. Arts and Humanities in Higher Education, 7(1), 9-27.

Grant, B. M. (2010) Improvising together. Arts and Humanities in Higher Education, 9(3), 271-288.

Jarvis, J., Lane, D. \& Fillery-Travis, A. (2006) The case for coaching - making evidence-based decisions on coaching, (CIPD).

Jarzabkowski, P., Mohrman, S. \& Scherer, A. (2010) Organization studies as applied science: The generation and use of academic knowledge about organizations introduction to the special issue. Organization Studies, 31(9-10), 9-10.

Kameen, P. (1995) Studying professionally: Pedagogical relationships at the graduate level. College English, 57(4), 448-460.

Kealey, T. (1996) The economic laws of scientific research, (Houndmills, Basingstoke, Hampshire; New York, Macmillan Press ; St. Martin's Press).

Knorr-Cetina, K. (1999) Epistemic cultures : How the sciences make knowledge, (Cambridge, Mass., Harvard University Press).

Lane, D. \& Corrie, S. (2006) The scientist practitioner, (New York, Routledge).

Lee, A. (2008) How are doctoral students supervised? Concepts of doctoral research supervision. Studies in Higher Education, 33(3), 267-281.

Lee, A. (2010) New approaches to doctoral supervision: Implications for educational development. EDUCATIONAL DEVELOPMENTS, 11(3), 18-23.

Lester, S. (2004) Conceptualising the practitioner doctorate. Studies in Higher Education, 29(5), 757-770.

Macey, W. H. \& Schneider, B. (2008) The meaning of employee engagement. Industrial and Organizational Psychology, 1(1), 3-30.

Maxwell, T. O. M. (2003) From first to second generation professional doctorate. Studies in Higher Education, 28(3), 279.

Maxwell, T. W., Green, B. \& Shanahan, P. J. (2001) Doctoral education and professional practice : The next generation?, (Armidale, N.S.W., Kardoorair Press).

Roberts \& Bywater (1954) The rhetoric and the poetics of aristotle, (Modern Library).

Ruona, W. E. A. \& Gilley, J. W. (2009) Practitioners in applied professions: A model applied to human resource development. Advances in Developing Human Resources, 11(4), 438-453.

Rynes, S. L., Bartunek, J. M. \& Daft, R. L. (2001) Across the great divide: Knowledge creation and transfer between practitioners and academics. Academy of Management Journal, 44(2), 340-355.

Salter, A., Committee Of, V.-C., Principals of the Universities of the United, K., University of Sussex. Science Policy Research, U. \& Higher Education Funding Council For, E. (2000) Talent, not technology : Publicly funded research and innovation in the uk, (London, CVCP).

Schatzki, T. R., Knorr-Cetina, K. \& Savigny, E. V. (2001) The practice turn in contemporary theory, (New York, Routledge). 
Schön, D. A. (1983) The reflective practitioner: How professionals think in action, (Basic Books).

Scott, I. (2010) But i know that already: Rhetoric or reality the accreditation of prior experiential learning in the context of work-based learning. Research in PostCompulsory Education, 15(1), 19 - 31.

Stephenson, J., Malloch, M. \& Cairns, L. (2006) Managing their own programme: A case study of the first graduates of a new kind of doctorate in professional practice. Studies in Continuing Education, 28(1), 17 - 32.

Tennant, M. (2004) Doctoring the knowledge worker. Studies in Continuing Education, 26(3), 431-441.

Trullen, J. \& Bartunek, J. (2007) What a design approach offers to organization development. The Journal of Applied Behavioral Science, 43(1), 23-40.

Van De Ven, A. H. (2007) Engaged scholarship : A guide for organizational and social research, (Oxford; New York, Oxford University Press).

Wasserman, I. C. \& Kram, K. E. (2009) Enacting the scholar-practitioner role. The Journal of Applied Behavioral Science, 45(1), 12-38.

Zoë, B. (2009) Theology and the researching professional. Theology, 112(869), 333-343.

Total word count (including references) $=6710$ 